une revue Gallia

Nouvelle-Aquitaine | 2013

\title{
Malemort-sur-Corrèze - Ville médiévale
}

Prospection thématique (2013)

\section{Dimitri Paloumbas-Odile}

\section{(2) OpenEdition \\ Journals}

Édition électronique

URL : https://journals.openedition.org/adlfi/16088

ISSN : 2114-0502

Éditeur

Ministère de la Culture

Référence électronique

Dimitri Paloumbas-Odile, « Malemort-sur-Corrèze - Ville médiévale » [notice archéologique], ADLFI.

Archéologie de la France - Informations [En ligne], Nouvelle-Aquitaine, mis en ligne le 14 janvier 2016,

consulté le 29 juillet 2021. URL : http://journals.openedition.org/adlfi/16088

Ce document a été généré automatiquement le 29 juillet 2021.

(c) ministère de la Culture et de la Communication, CNRS 


\section{Malemort-sur-Corrèze - Ville médiévale}

Prospection thématique (2013)

Dimitri Paloumbas-Odile

\section{NOTE DE L'ÉDITEUR}

Organisme porteur de l'opération : Hadès

Paloumbas D. 2013 : Malemort-sur-Corrèze, Corrèze (19), étude documentaire et de topographie archéologique de la ville médiévale, rapport final d'opération archéologique, Hadès, Limoges, SRA Limousin, 4 vol. [RAP01882]

1 Cette étude documentaire et de topographie archéologique, commandée par la municipalité de Malemort-sur-Corrèze, fait suite à une campagne de fouilles archéologiques réalisée en 2011 sur le castrum de Malemort. Ces fouilles ayant confirmé le potentiel archéologique du site castral, la municipalité a souhaité compléter les recherches par une étude focalisée sur le contexte urbain associé au castrum.

2 Le bourg médiéval de Malemort (fig. 1) est situé sur la rive droite de la Corrèze, au nord-ouest de la RD 2089 (avenue Jean-Jaurès). L'agglomération s'est développée en contrebas du site castral, qui occupe le sommet d'un éperon de confluence où se rejoignent la Corrèze et le ruisseau des Saulières. Les principales habitations sont regroupées au sud-ouest de l'éperon. Une deuxième concentration d'habitats peut être restituée au nord de la plate-forme castrale, au débouché d'une route de crête ancienne d'orientation générale nord-sud (lieu-dit Montemart). 
Fig. 1 - Cadastre napoléonien géoréférencé de Malemort

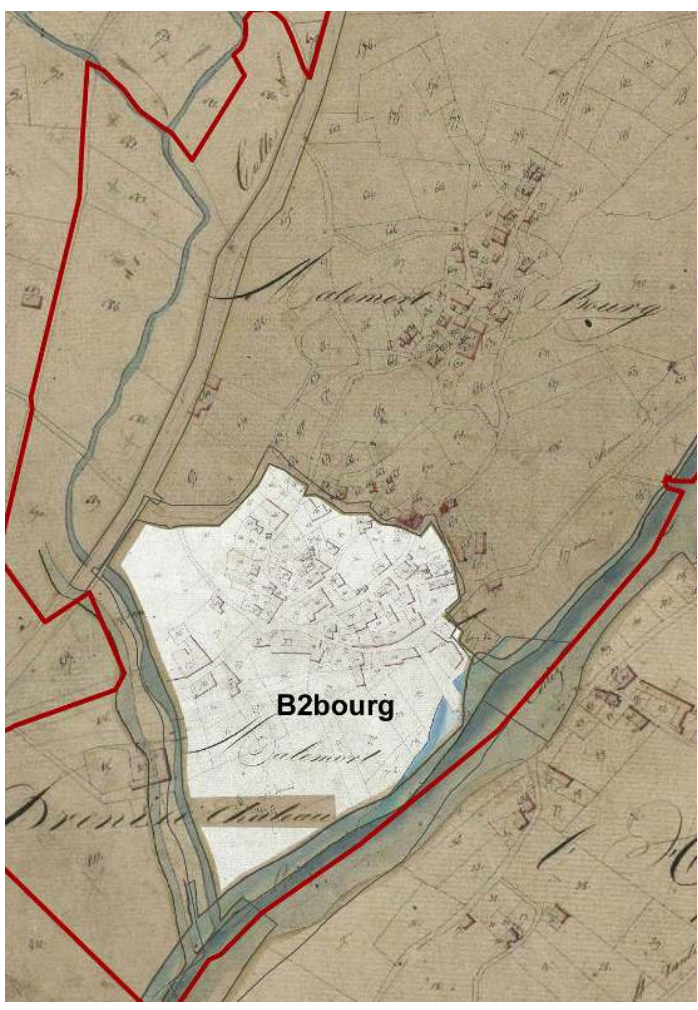

SIG : N. Tranchant, E. Dellong (Hadès).

3 La problématique de cette étude était de restituer, dans ses grandes lignes, l'évolution morpho-historique du village castral de Malemort depuis le Moyen Âge jusqu'à la fin de l'époque moderne. Ce travail comprend une recherche en archives destinée à compléter les informations historiques produites dans le cadre du PCR "Castrum » dirigé par C. Rémy, et du rapport d'opération archéologique de 2012. Un inventaire archéologique des édifices civils et religieux du bourg castral a également été effectué. Un autre volet de la demande concernait la réalisation d'un système d'informations géographiques (SIG) destiné à élaborer des cartes thématiques.

Le bilan de cette étude est globalement positif. L'analyse des sources écrites a tout d'abord permis de cerner une première phase de peuplement, à la charnière des $\mathrm{XII}^{\mathrm{e}}$ et $\mathrm{XIII}^{\mathrm{e}} \mathrm{s}$. Le décompte des maisons a révélé que le bourg comportait au moins quarante logis vers 1200 . Ces logis étaient insérés dans un espace clos par plusieurs portes et protégé par un fossé. D'après l'inventaire archéologique, la zone dite « de Montemart » était occupée dès le $\mathrm{xIII}^{\mathrm{e}} \mathrm{s}$. La plus ancienne maison médiévale de cette zone serait celle de la parcelle 168 , mais on peut supposer que des maisons existaient dès le XIII ${ }^{\mathrm{e}}$ s., au nord du croisement de la rue de Montemart et de la rue des Brabançons. Dans le bourg proprement dit, l'édifice le plus ancien pourrait être celui des parcelles 92, 93 (fig. 2 et 3) et 67 (fig. 4). 
Fig. 2 - Vue générale du logis des parcelles 92 et 93 depuis l'est

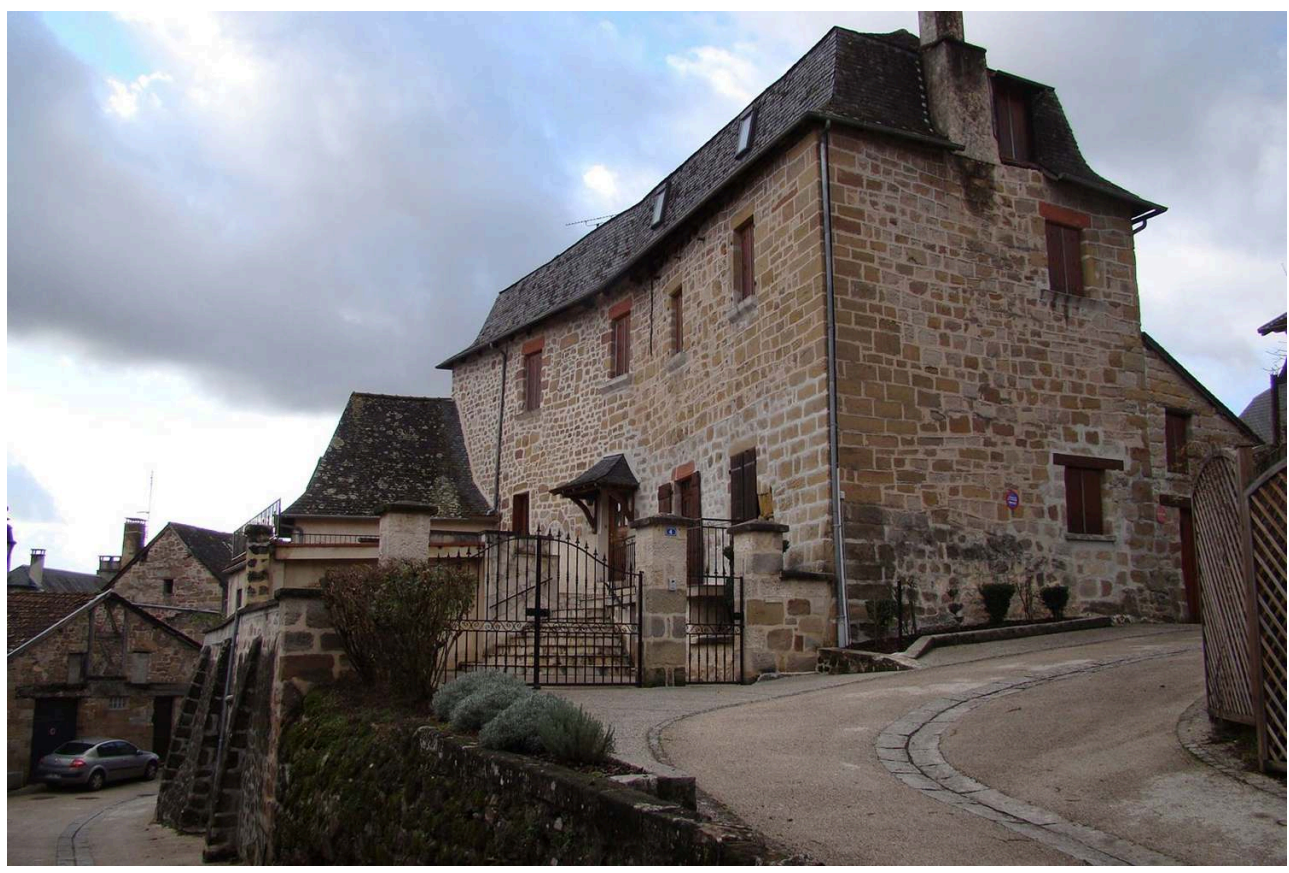

Cliché : D. Paloumbas-Odile (Hadès).

Fig. 3 - Logis des parcelles 92 et 93, relevé partiel de l'élévation nord-ouest

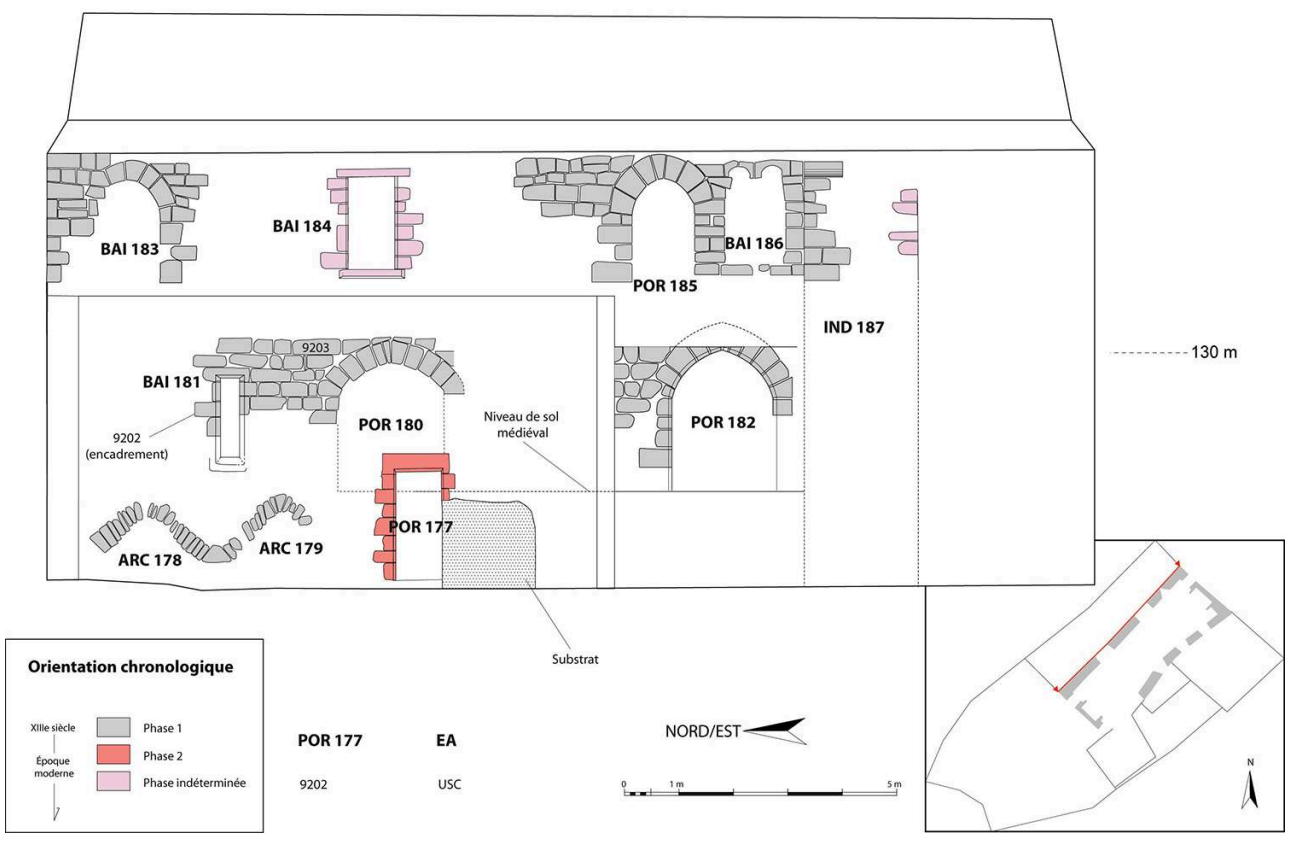

DAO et relevés de terrain : D. Paloumbas-Odile, d'après une orthophotographie de M. Dutailly, (Hadès). 
Fig. 4 - Portes médiévales du logis de la parcelle 67

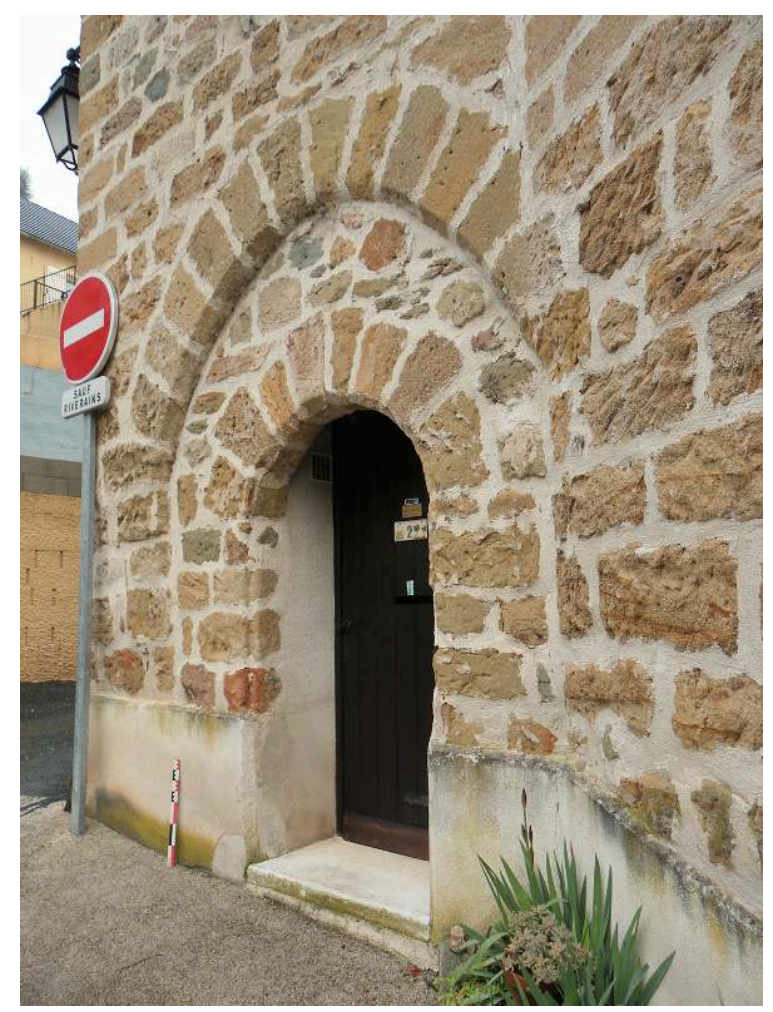

Cliché : D. Paloumbas-Odile (Hadès).

5 À défaut de sources, l'activité foncière n'est pas documentée durant une période comprise entre le milieu du XIV ${ }^{\mathrm{e}} \mathrm{s}$. et le début du $\mathrm{XV}^{\mathrm{e}} \mathrm{s}$. À partir de 1440-1450, l'étude historique s'appuie sur un nombre important de reconnaissances foncières. Ces documents contiennent en outre des informations essentielles pour l'étude du bourg, comme la première mention connue du pont de Malemort, en 1443. Sur le plan archéologique, plusieurs vestiges de portes, de baies ou de cheminées peuvent être associés à cette séquence de reconstruction. Celle-ci semble avoir perduré jusqu'au milieu du XVI ${ }^{\mathrm{e}} \mathrm{s}$.

6 Une reprise de l'activité foncière est perceptible vers le milieu du XVII ${ }^{\mathrm{e}} \mathrm{s}$. Cette période correspond à l'apparition des premiers registres de notaires. Ceux-ci font état de nombreuses transactions portant sur des maisons du bourg, qu'il s'agisse de prix-fait de réparation, de vente ou d'échange. Au XVIII ${ }^{e}$ s., le bourg connaît peut-être des difficultés économiques. Selon plusieurs sources, le pont et la barque destinés au franchissement de la Corrèze restent détruits durant plusieurs décennies. L'implantation d'une magnanerie dans l'ancien château de Bréniges et la construction d'une usine destinée à la production de tissus de gaze et de mouchoirs de soie après 1760 , marquent le début d'un certain renouveau économique. Les aménagements de la route de Sainte-Féréole et de la «traverse » de Malemort ont aussi probablement contribué au désenclavement de la ville à la même période. L'inventaire a permis de voir que de nombreuses maisons avaient effectivement été construites ou reconstruites au XIX ${ }^{e} s$. 


\section{INDEX}

lieux https://ark.frantiq.fr/ark:/26678/pcrtSEeAipsBlD, https://ark.frantiq.fr/ark:/26678/ crtzlfS4gXnfB, https://ark.frantiq.fr/ark:/26678/pcrtoUFSEfHxpi, https://ark.frantiq.fr/ark:/ 26678/pcrts8snL5LQbE, https://ark.frantiq.fr/ark:/26678/pcrt5xYGzREPFh

Année de l'opération : 2013

nature https://ark.frantiq.fr/ark:/26678/crtcYIBmBlBPH, https://ark.frantiq.fr/ark:/26678/ pcrtaodMT8j830

chronologie https://ark.frantiq.fr/ark:/26678/pcrtAQyKm9qosx, https://ark.frantiq.fr/ark:/ 26678/pcrtPSEEZSBEJp, https://ark.frantiq.fr/ark:/26678/pcrt59R77d1H15

sujets https://ark.frantiq.fr/ark:/26678/pcrtPPPS9ErMrW

\section{AUTEURS}

\section{DIMITRI PALOUMBAS-ODILE}

Hadès 